Revista da Rede Brasileira de História da Geografia e Geografia Histórica

$14 \mid 2020$

História da cartografia amazônica

\title{
Região amazônica
}

Metodologia para o estudo da evolução cartográfica

Amazon región: Methodology for the study of cartographic evolution

Región Amazónica: Metodología para el estudio de la evolución cartográfica

Région amazonienne: Méthodologie pour l'étude de l'évolution cartographique

\section{Jorge Pimentel Cintra}

\section{OpenEdition}

Journals

\section{Edição electrónica}

URL: https://journals.openedition.org/terrabrasilis/7278

DOI: 10.4000/terrabrasilis. 7278

ISSN: 2316-7793

\section{Editora}

Rede Brasileira de História da Geografia e Geografia Histórica

\section{Refêrencia eletrónica}

Jorge Pimentel Cintra, «Região amazônica», Terra Brasilis [Online], 14 | 2020, posto online no dia 31 dezembro 2020, consultado o 05 dezembro 2022. URL: http://journals.openedition.org/terrabrasilis/ 7278 ; DOI: https://doi.org/10.4000/terrabrasilis.7278

Este documento foi criado de forma automática no dia 5 dezembro 2022.

All rights reserved 


\title{
Região amazônica
}

\author{
Metodologia para o estudo da evolução cartográfica
}

Amazon región: Methodology for the study of cartographic evolution

Región Amazónica: Metodología para el estudio de la evolución cartográfica

Région amazonienne: Méthodologie pour l'étude de l'évolution cartographique

\author{
Jorge Pimentel Cintra
}

\section{Introdução}

1 O presente trabalho recolhe os resultados de um projeto que tinha por objetivo estudar a evolução da cartografia do rio Amazonas, de 1500 a 1750, servindo-se dos mapas disponíveis em mapotecas digitais, notadamente a Biblioteca Nacional (Brasil) e a John Carter Brown Library (Estados Unidos).

2 A metodologia consistiu na estruturação cronológica e de dependência através do exame dos mapas da Biblioteca Nacional, depois complementada e reformulada pela pesquisa em outras bases. Esse exame consistiu no estudo do conteúdo e forma das feições geográficas, com foco no rio Amazonas, já que está presente na maioria das representações. Para isso, empregamos a metodologia e técnica de leitura de mapas descrita em outros de nossos trabalhos (Cintra, 2012b, 2015, 2016).

3 Para a realização de tal tarefa, parte-se do princípio de que não existe mapa sem informação (de índios, de viajantes, de aventureiros, de missionários) e que uma informação presente em um mapa tem sua origem, ou na imaginação, ou em viagens realizadas. Nesse estudo comparativo, os erros e equívocos, comparados a mapas atuais, são muito eloquentes para identificar cópias, a partir do modelo ou protótipo (mapa estruturante) que apresentou esse engano pela primeira vez.

Esses mapas estruturantes também se relacionam com a evolução da tecnologia, tanto de equipamentos e técnicas - notadamente a maneira como se determinavam as longitudes - como dos métodos de cálculo. Em função disso foram identificados alguns mapas marcantes, que serão aqui analisados. 
5 Eventos políticos também se refletem na mudança da toponímia e nas linhas de fronteiras, mostrando como os mapas podem ser instrumentos de disputas por território, entre países, por exemplo, ou mesmo refletir uma mudança de concepção da ocupação do espaço.

6 Concluímos o texto mostrando, dada a riqueza dos mapas, a importância de estudá-los sob diversos ângulos e aspectos. A cartografia histórica e a história da cartografia somam-se e devem ser vistas como complementares e não a partir de visões exclusivistas.

\section{Primeiros paradigmas cartográficos}

7 Para estabelecer um estudo comparativo e determinar mapas estruturantes, fixou-se a atenção sobretudo no rio Amazonas, que sempre chamou a atenção de exploradores e cartógrafos, desde a descoberta de sua foz por Vicente Yanés Pinzón em 1499-1500. As sucessivas explorações acrescentaram dados e informações que foram sendo incorporadas aos novos mapas. No início e até depois da viagem de Francisco de Orellana (1542) representa-se a foz desse rio e, de acordo com a maior ou menor imaginação do cartógrafo, também o seu curso com diversas direções; por exemplo, no Universale, de 1546 (Figura 1), o traçado é de sul a norte, com as nascentes na Patagônia. De onde procede esse desenho errôneo? Certamente da imaginação do cartógrafo, talvez influenciado pelo desenho do rio Nilo na África, que era conhecido, pelo menos em um trecho significativo. Por outro lado, os Andes e as serras do litoral, mal conhecidas, forçam um desenho na direção norte-sul. As informações de Orellana não haviam chegado ao autor desse mapa. 
Figura 1: Giacomo Castaldi, Vniversale (vista parcial), Veneza, 1546

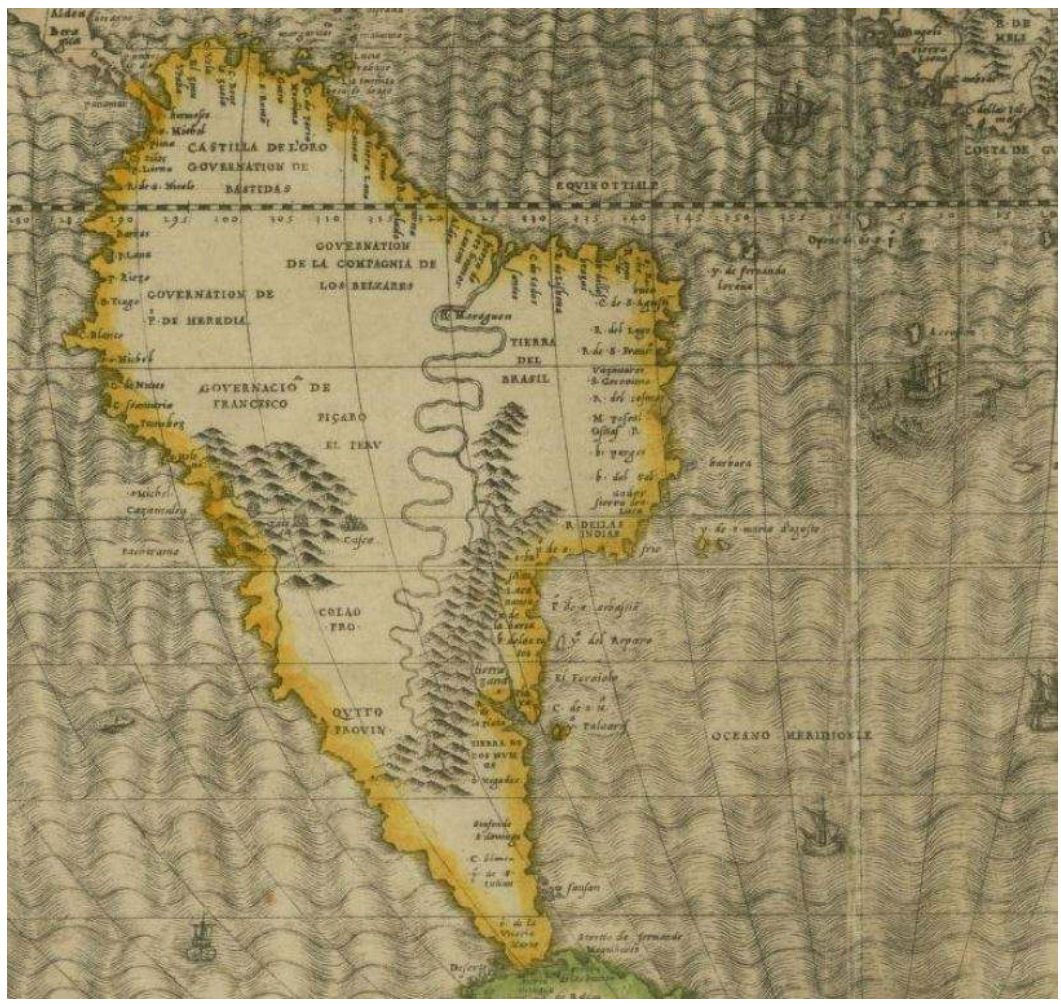

Fonte: John Carter Brown Library, disponível em: https://jcb.lunaimaging.com/luna/servlet/s/h81d23

8 Por sua vez, o mapa, Tierra Nova (Figura 2), da Biblioteca Nacional, segue basicamente esse protótipo, ainda que modificando o tipo de projeção e os topônimos. Há outros mapas na John Carter Brown que seguem o mesmo protótipo. 
Figura 2: Girolamo Ruscelli, Tierra Nova, (c.) 1548

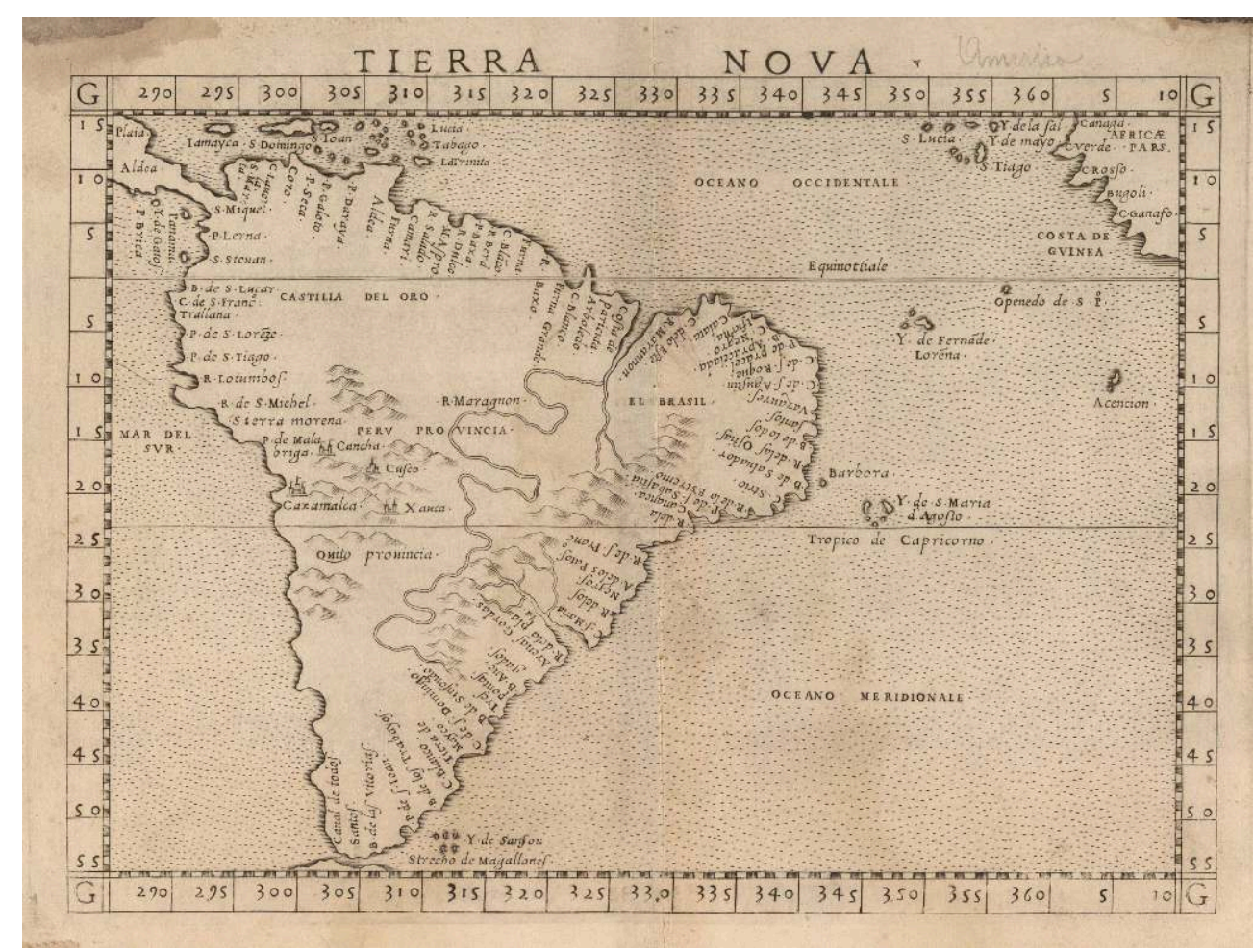

Fonte: Biblioteca Digital da Biblioteca Nacional do Rio de Janeiro. Disponível em: http:// acervo.bndigital.bn.br/sophia/index.asp?codigo_sophia=13

\section{Novos protótipos: Diogo Homem e Lucas de Quirós}

9 Com a descida de Orellana, de São Francisco de Quito até o oceano Atlântico, fica conhecida a orientação geral de oeste para leste desse trecho do rio. Essas informações começam então a refletir-se na cartografia junto com outras coletadas na viagem: o traçado serpenteado pouco abaixo da linha do equador; notícias e nomes dos principais afluentes e das tribos indígenas de suas margens; a existência de grande quantidade de ilhas e lagos.

Essas ideias refletem-se no mapa de Diogo Homem, 1558 (Figura 3), no que poderíamos chamar mapa conceitual, pois, mais do que precisão cartográfica no traçado, transmite conceitos, certos a grandes rasgos: direção leste oeste, serpenteando, pouco abaixo da linha do equador, muitas ilhas, afluentes, que, nesse caso, desembocam nas curvas salientes. 
Figura 3: Diogo Homem, Atlas (parte), 1558

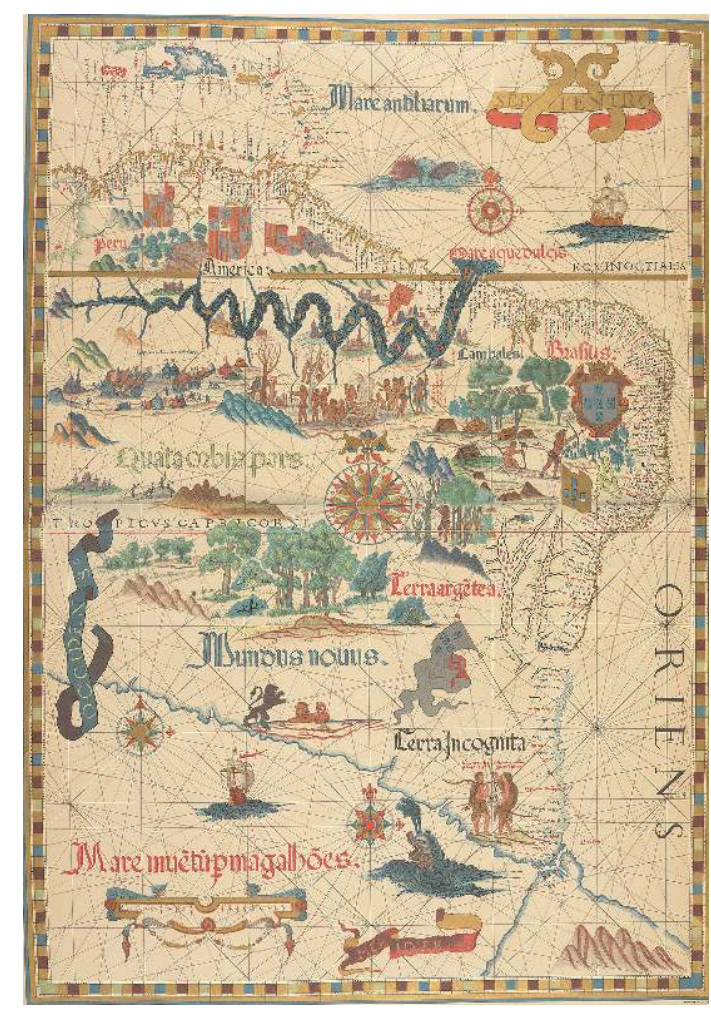

Fonte: Bibliothèque de Genève. Disponível em: http://doc.rero.ch/record/308702

11 Ao lado de acertos e linhas gerais, estão presentes alguns erros, como o de supor que essa corrente única de água de Quito ao oceano Atlântico é um só rio e não um curso afluente (rio Coca) que deságua no Napo, que, por sua vez, é tributário do Marañon. Esse topônimo, com o surgimento do mito das mulheres guerreiras, passa a denominarse Amazonas. Em outros mapas aparecem novos mitos, como as lendas do lago Eupana, do Eldorado ou Lagoa Dourada, e também anões, gigantes, homens com os pés voltados para trás. Aparece também o louvor das riquezas e potencialidades que se intuíam ou se imaginavam, para essa região: ouro, prata, minerais, frutas, plantas medicinais, caça, pesca.

\section{Ortelius (1595) e Lucas de Quirós}

12 Um novo paradigma surge com Abraham Ortelius, em mapa de 1595. A fama do cartógrafo do rei da Espanha ajudou a construir o paradigma. Elaborado no período da União Ibérica, o mapa recolhe informações da cartografia portuguesa, associadas a outras espanholas, como o curso dos rios Paraná e Paraguai, seus afluentes e muitos topônimos. Na região amazônica, procurando conciliar informações conflitantes, ele desenha o rio Amazonas, como em protótipos anteriores, mas acrescenta um rio Maranhão, nascendo nas proximidades de Lima, comunicando-se com o Amazonas em seu curso médio e desaguando na futura baía de São Luís, dando origem a um dos atuais estados brasileiros (Maranhão). 
Figura 4: Abraham Ortelius, Americae sive Novi Orbis, 1595

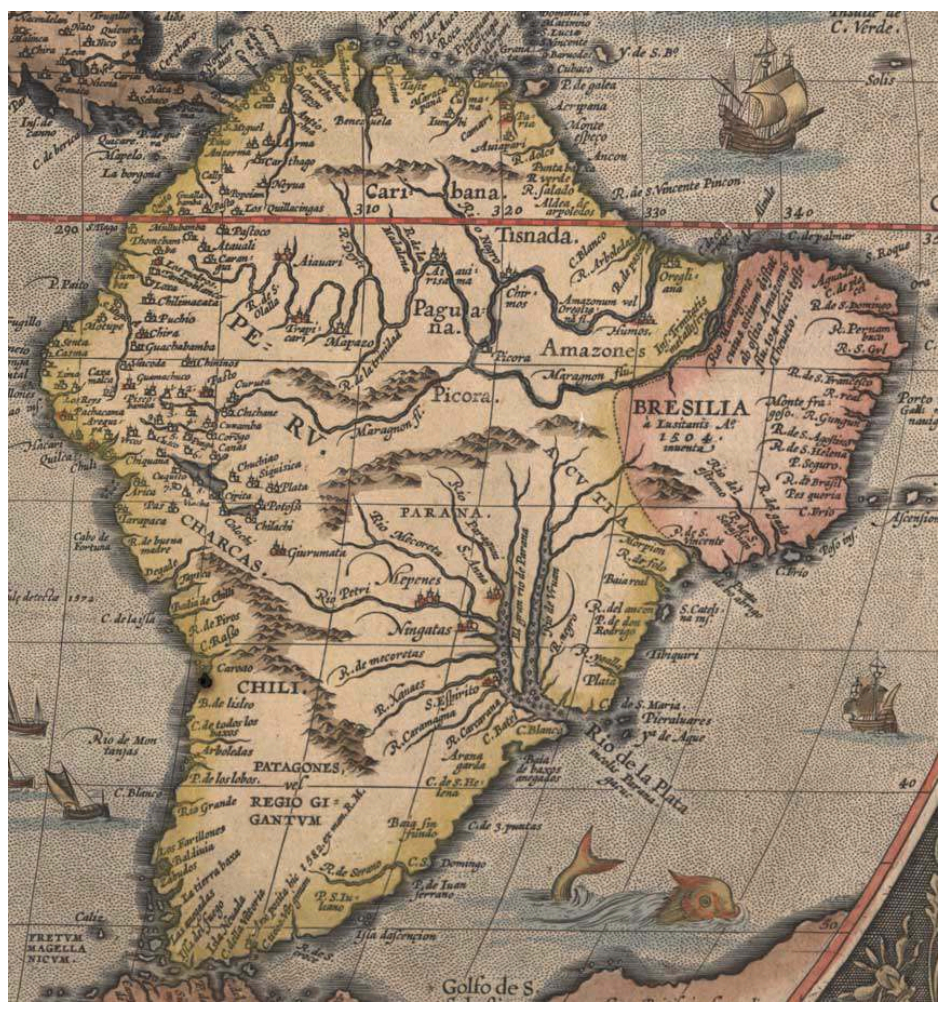

Fonte: Biblioteca Digital - Biblioteca Nacional do Rio de Janeiro. Disponível em: http:// acervo.bndigital.bn.br/sophia/index.asp?codigo_sophia=1

Passemos a outro: ainda que impreciso em inúmeros pontos, o melhor mapa baseado em novas informações da América espanhola, também elaborado no período da União Ibérica, é a Carta da América Meridional (Figura 5), traçada em Lima pelo cartógrafo-mor do vice-reino do Peru, Lucas de Quirós, filho do explorador português Pedro de Queiroz, que esteve a serviço da Espanha. Nesse mapa, além dos aspectos verdadeiros (ilhas, incluindo as da foz e sinuosidades), vê-se que ainda se considerava o Amazonas nascendo perto de Quito e se consigna também o engano de Ortelius, com certa modificação: mais do que dois rios, representa uma bifurcação do Amazonas na altura do rio Madeira, após uma grande ilha (Tupinambarana), sendo que o segundo braço leva o nome de Marañon ou Maranhão. Cadeias de montanhas e afluentes menores, afora os Andes e os grandes rios, são desenhados mais como conceitos do que como realidade geográfica. 
Figura 5: Lucas de Quirós, - Carta da América Meridional, 1618

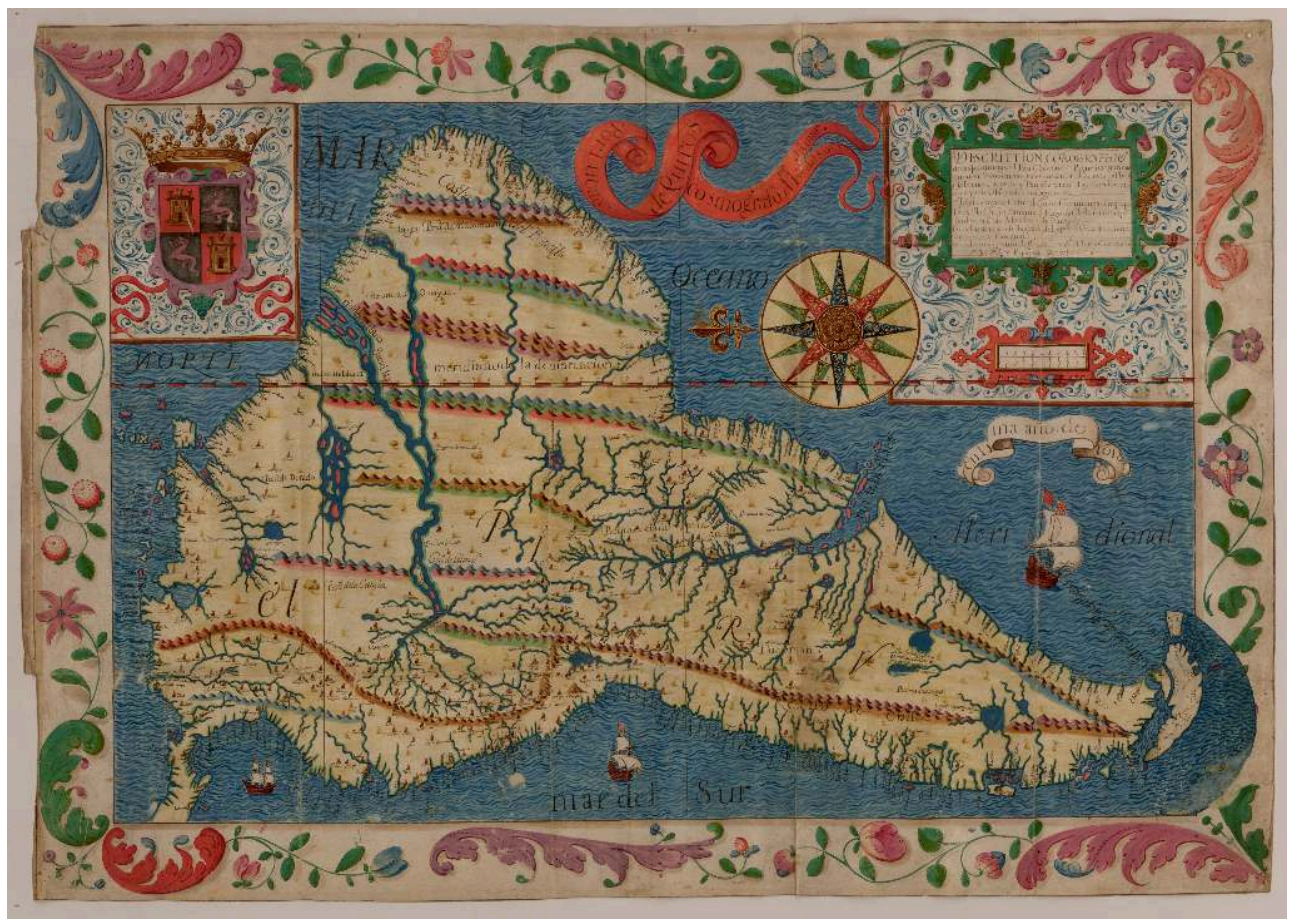

Fonte: Real Biblioteca do Palácio Real de Madri. Disponível em: https://www.realbiblioteca.es/es/ node/286\#\&gid=1\&pid=6

\section{Mais informações e os mapas do Conde de Pagan e o de Sanson}

Para um melhor desenho da hidrografia amazônica seriam necessárias informações mais precisas. Estas afluem com a expedição de Pedro Teixeira (1637-1639), de Belém a Quito e retorno. Nessa volta veio com ele o padre Acuña, jesuíta, que deixou extenso relato (Figura 6), em 1641, sobre a descida fluvial, assinalando alturas (latitudes) de diversas localidades, bem como as distâncias em léguas entre os locais. A seguir, em trabalho admirável, Pagan (1656), esse cartógrafo transformou essas distâncias em longitudes e traçou, com fundamento, o primeiro mapa dessa região num sistema de projeção cartográfica, com coordenadas geográficas: com ele, e não com La Condamine, começa a cartografia científica do Amazonas: ver Cintra (2011). 


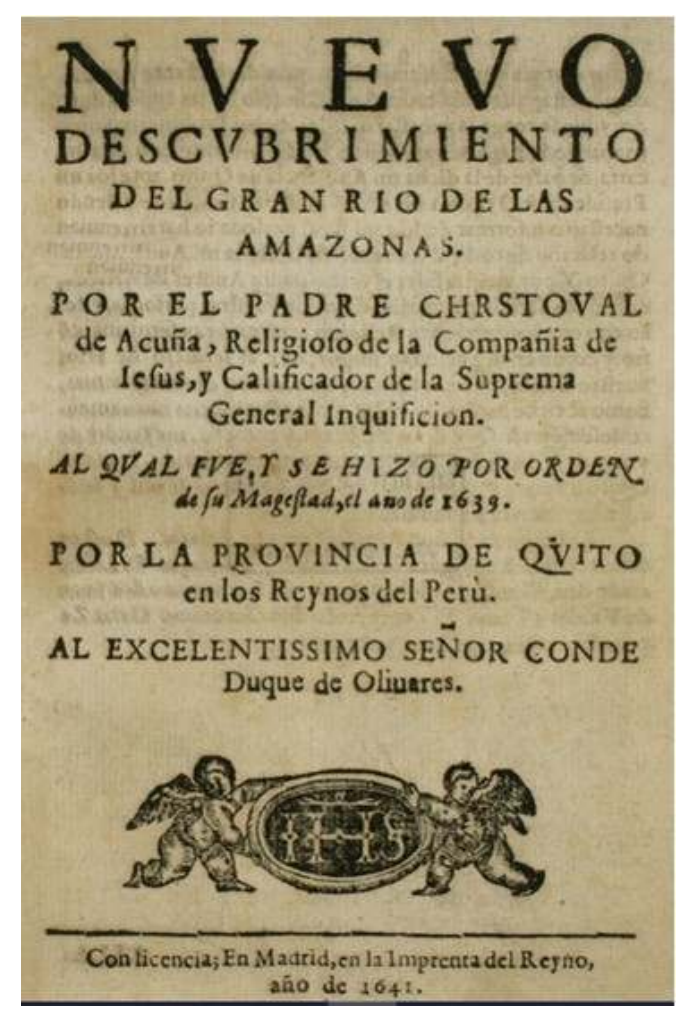

Fonte: Disponível na Biblioteca Digital da Biblioteca Nacional do Rio de Janeiro http:// acervo.bndigital.bn.br/sophia/index.asp?codigo_sophia=508

o Conde de Pagan serviu-se dos dados do padre Acuña para o traçado do seu mapa, levantando-se aí uma questão preliminar: quem é o autor de um mapa? Quem levantou os dados ou quem o desenhou, pois ambos contribuíram para sua feitura? Tentando responder: o levantamento dos dados é uma tarefa trabalhosa, que requer a medição de latitudes, rumos e distâncias e, mais tarde, de longitudes. O desenho de um mapa, em diversas circunstâncias, é uma tarefa simples, em outras não, e requer conhecimentos e cálculos, além da técnica de desenho. 0 problema já se colocava com Ptolomeu: os livros I e VIII de sua Geografia apresentam a maneira de construir uma rede de meridianos e paralelos para três tipos de projeção (é, por assim dizer, a teoria matemática e geométrica subjacente); os demais livros, de II a VII, contêm os dados, isto é, lista de localidades com coordenadas (latitude e longitude): uma vez estabelecida a rede de coordenadas, basta demarcar cada ponto no mapa e uni-los adequadamente. Depois de Ptolomeu surgiram outras projeções, algumas delas mais simples, como a Carta Plana Quadrada, com eixos perpendiculares e igual espaçamento da quadrícula, facilitando enormemente o desenho de um mapa a partir das coordenadas.

No caso concreto, o próprio Acuña não conseguiu realizar um desenho a partir de suas informações, pois não atinou com uma maneira de extrair deles as longitudes; e nisso reside a genialidade de Pagan, que foi o primeiro a desenvolver uma metodologia para isso (Figura 7). 
Figura 7: Esquema utilizado pelo Conde de Pagan pata calcular as longitudes

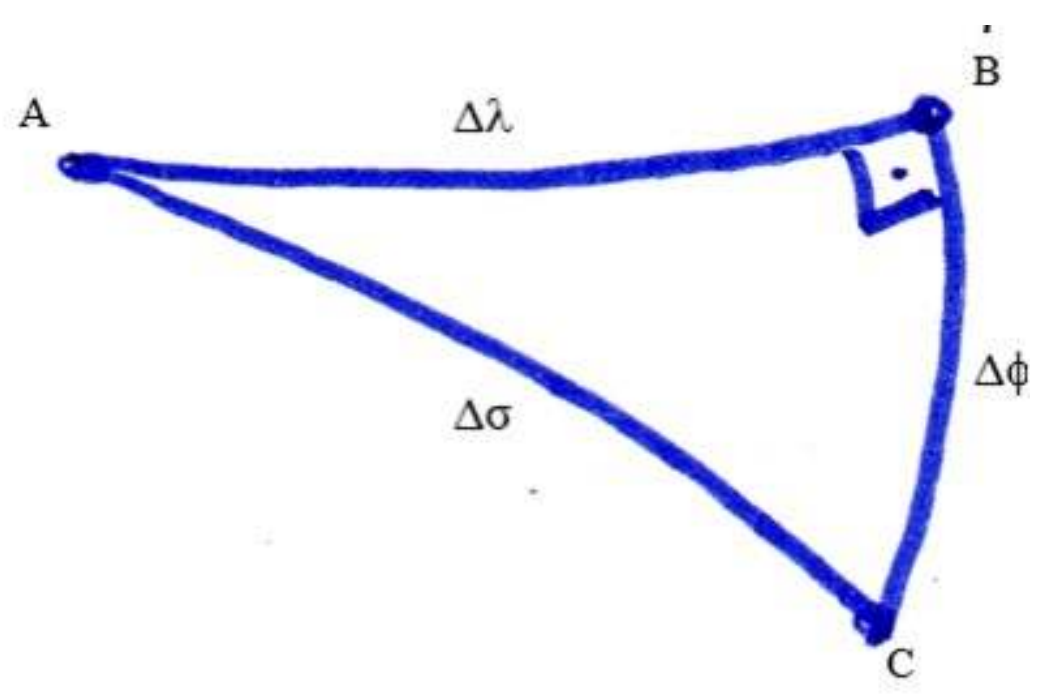

Fonte: $\mathrm{O}$ autor

17 Parte-se de uma longitude arbitrada (por exemplo, o ponto A) e dadas as léguas estimadas (s) e as latitudes de A e C (portanto também $\Delta \phi$ ), calcula-se a diferença de longitudes $(\Delta \lambda)$ pela fórmula (1):

$\cos \Delta \lambda=\cos (\Delta \sigma) / \cos \Delta \phi$

18 Onde:

$\Delta \lambda$ - diferença de longitude a calcular

$\Delta \phi$ - diferença de latitude entre 2 pontos

$\Delta \sigma$ - distância em graus $=\mathrm{s} / 20$, sendo $\mathrm{s}$ o número de léguas estimadas de percurso e $20 \mathrm{o}$ número de léguas contidas em um grau

Assim, ele pôde desenhar o seu mapa (Figura 8). 


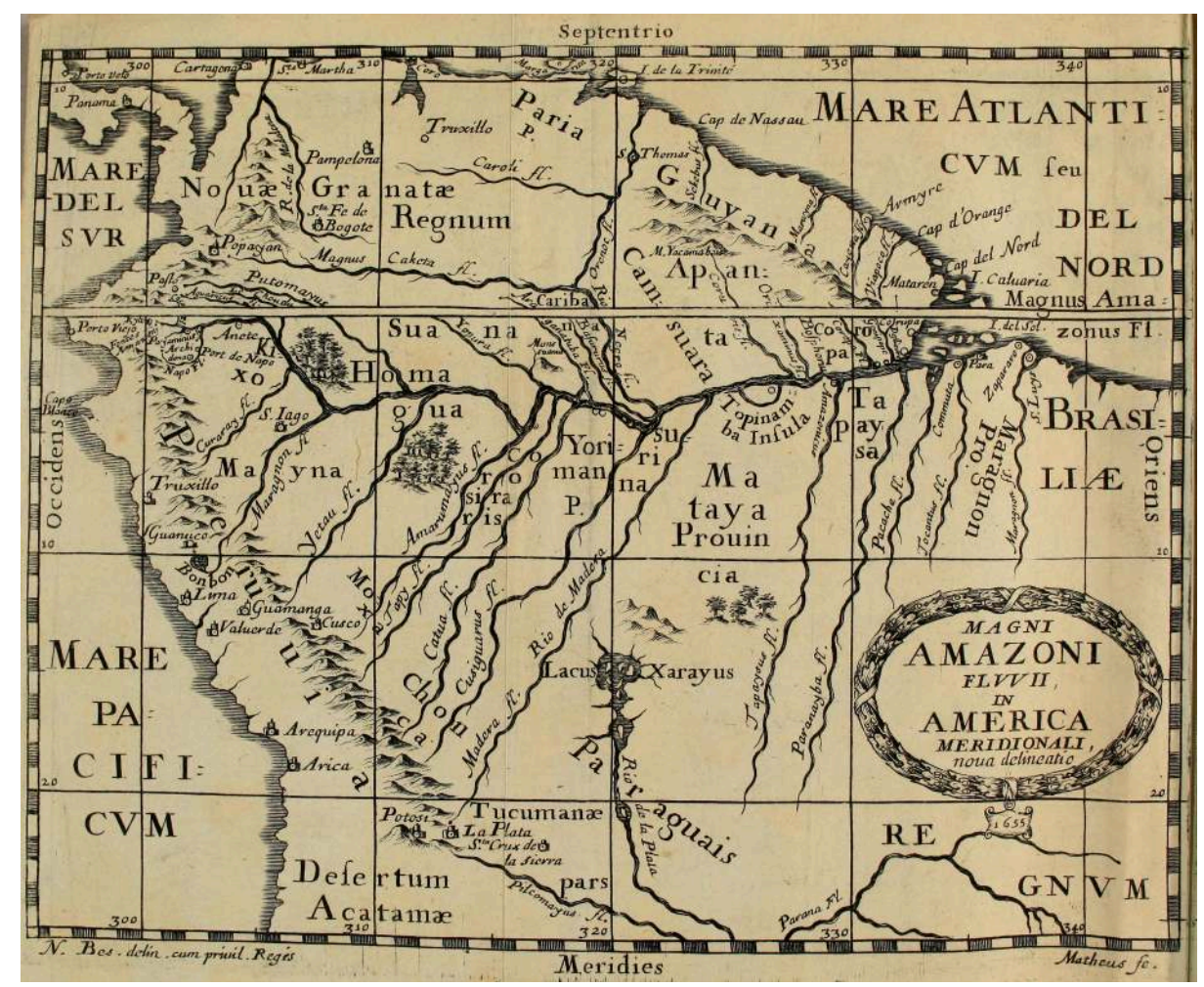

Fonte: John Carter Brown Library - Internet Archive. Disponível em: https://archive.org/details/ relationhistoriq00paga/page/n17/mode/2up

Depois disso, outros cartógrafos passaram a fazer o mesmo, não só com os dados do jesuíta e corrigindo alguma falha de Pagan, mas estendendo a metodologia para outros casos. Por esses cálculos e pelo desenho, o mapa em questão pode ser considerado da autoria de Pagan, baseado no relato de Acuña.

Por trabalhar com dados deficientes (exagero nas distâncias, erro nas coordenadas de origem) e apesar de tentar ajustes, esse mapa de Pagan apresenta valores que divergem dos valores atuais. Um mapa da época, citado por Pagan, dava para a extensão longitudinal da América do Sul o valor de 58을 enquanto os espanhóis davam $55^{\circ}$ e os portugueses $51^{\circ}$, valor aproximado adotado por Pagan para ajustar os dados de Acuña, mas ainda com erro por excesso, pois, na realidade, a extensão situa-se na casa dos $46^{\circ}$. Em latitude, a precisão situa-se em torno de $0,5^{\circ} \mathrm{e}$, em longitude, na casa de $2^{\circ}$, mais do que compatível com a metodologia empregada.

Mas, apesar de tudo, o mapa de Pagan não influenciou diretamente outros mapas. 0 protótipo para mapas futuros, aproveitando a fama e o posto de seu autor, foi o mapa de Nicolas Sanson, feito no ano seguinte (Figura 9) e empregando a mesma metodologia de Pagan, segundo pudemos comprovar (Cintra, 2014). 


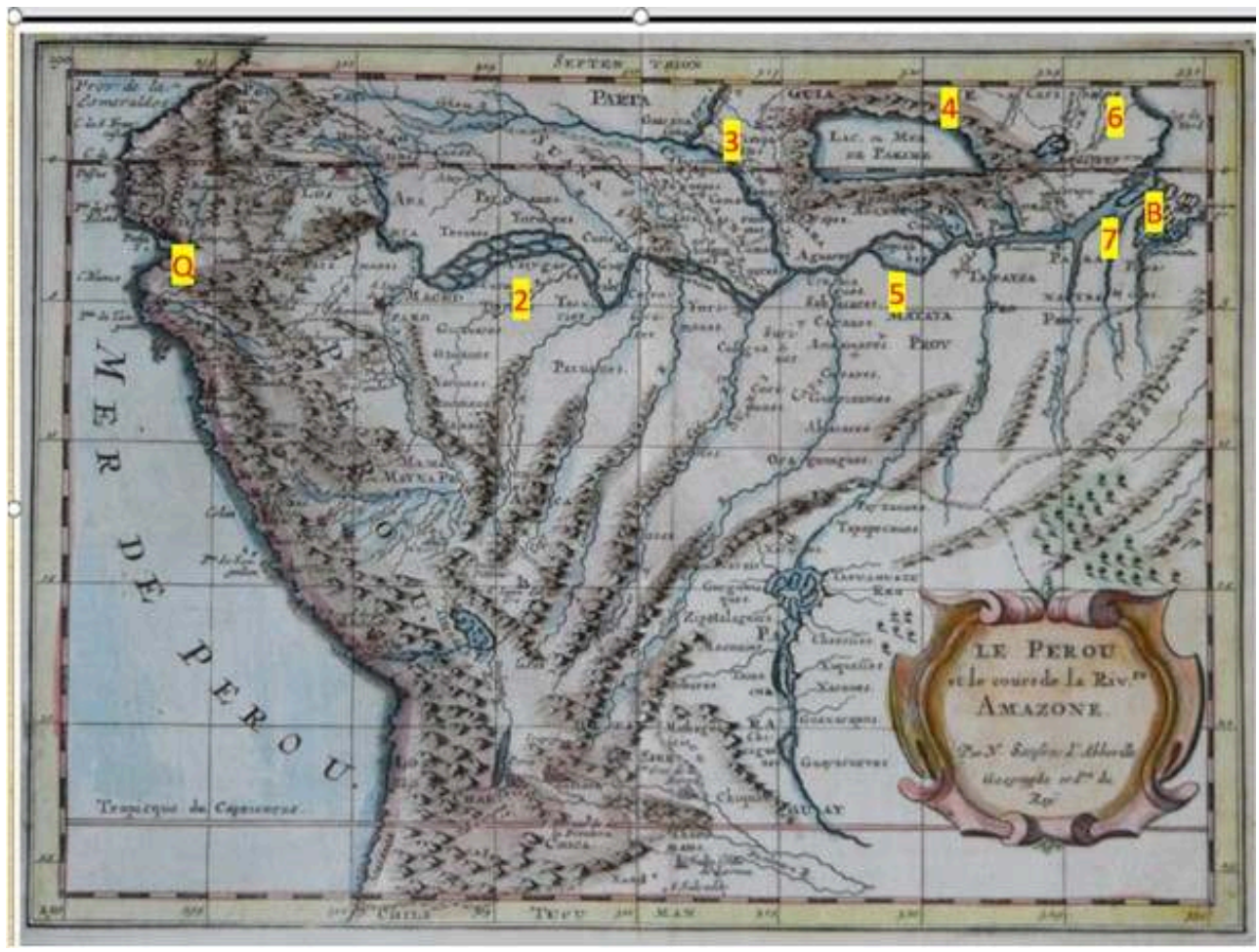

Fonte: 0 autor, a partir de mapa disponível em https://www.researchgate.net/figure/The-Peru-and-theCourse-of-the-Amazon-River-1656-Nicolas-Sanson_fig2_274360806

Na Biblioteca Nacional encontramos 14 mapas que se serviram desse protótipo e isso pode ser identificado pela semelhança ou quase identidade quanto à conformação dos seguintes pontos ou feições: rendilhado de ilhas na posição (2), da junção OrinocoAmazonas (3), do lago Parime (4), da ilha Tupinambarana (5), da região do Cabo norteOrange (6), do forte Curupá na margem direita e não na esquerda como deveria ser (7), das inúmeras ilhas na foz, em vez da ilha de Marajó (B).

\section{Passos em direção a uma cartografia exata: o mapa do padre Fritz}

Samuel Fritz, missionário jesuíta entre os Omáguas, percorreu esse rio até a sua foz. A primeira versão é de 1691, sendo, no entanto, mais conhecida a versão impressa de 1707 com o título El Gran Rio Marañon o Amazonas: foi com essa que trabalhamos (Figura 10).

24 É um mapa muito rico em informações textuais e em ornamentação, sem deixar de ter elementos técnicos salientes: possui projeção cartográfica e coordenadas geográficas e constitui uma melhora considerável em comparação com o mapa do Conde de Pagan ou ao de Sanson nos dois aspectos: abundância de informações e precisão geométrica. Pelo menos a versão de 1691 foi consultada e considerada por La Condamine, quando esse cientista francês desceu e realizou levantamentos no rio para desenhar o seu mapa.

Fritz, por ter percorrido pessoalmente esse rio em uma ampla extensão, foi o primeiro a identificar e cartografar o rio (Marañon) desde suas origens, identificando a corrente principal e passando o Napo para a condição de afluente. 


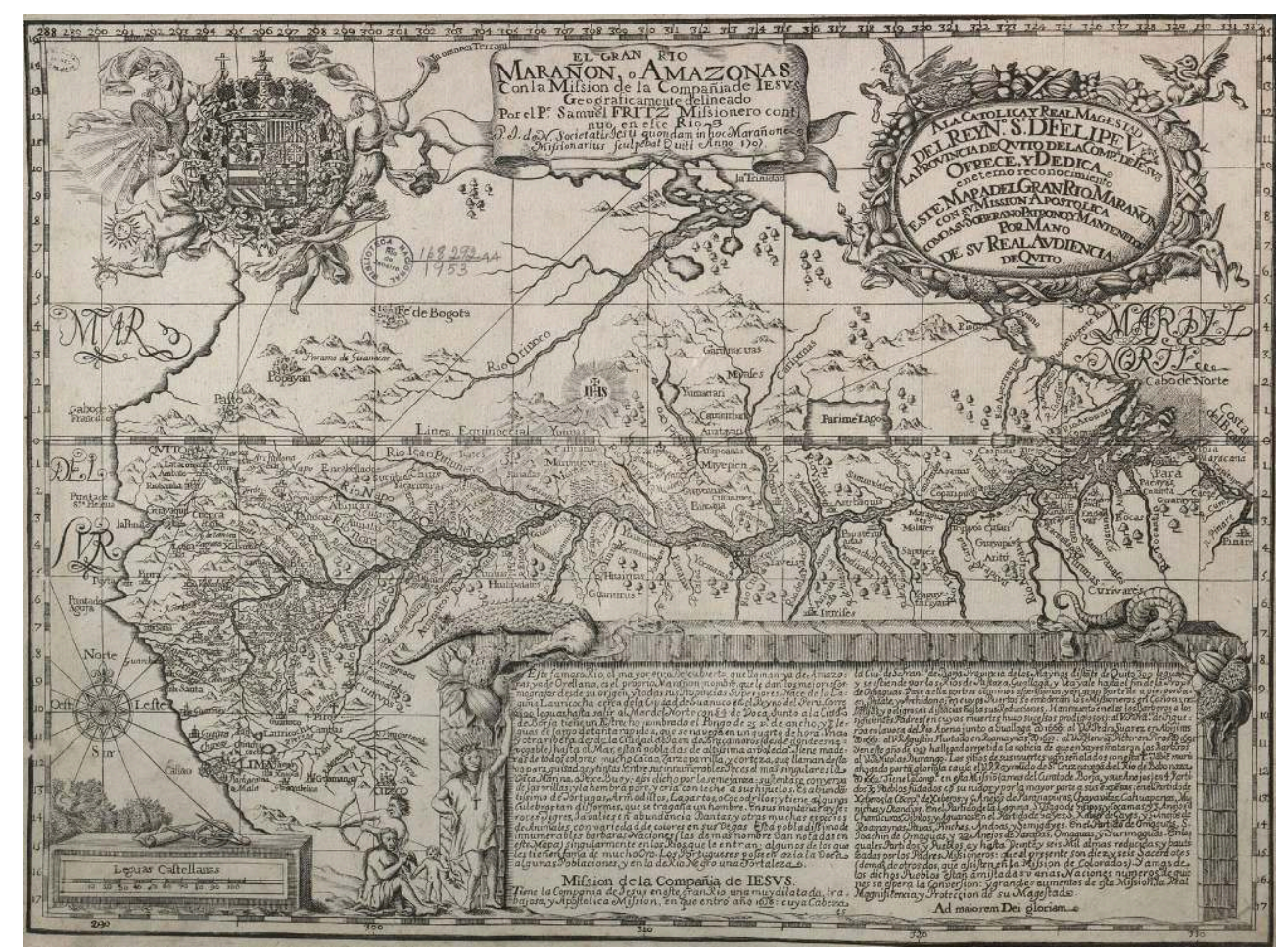

Fonte: Biblioteca Digital da Biblioteca Nacional do Rio de Janeiro http://acervo.bndigital.bn.br/sophia/ index.asp?codigo_sophia=29

Em função das comparações e comentários de La Condamine, como se verá, considerase, geralmente, que esse mapa é de pior qualidade, o que não é verdade. Em resumo, a precisão é de $0,4^{\circ}$ em latitude e cerca de $1^{\circ}$ em longitude.

\section{O mapa de La Condamine: longitudes astronômicas}

O Mapa do Pe. Fritz, ainda que preciso, foi levantado através de medições de latitudes, distâncias percorridas (por estimativa e sensibilidade prática) e rumos de cada trecho (bússola). Não contou com longitudes determinadas por observações astronômicas. Isso só aconteceria com a Carte du cours du Maragnon ou de la Grande Riviere de Amazones (1745), de La Condamine. Esse sábio francês, na volta da medição do arco de meridiano desceu o rio Amazonas medindo rumos, distâncias, latitudes e algumas longitudes. Em Paris publicou um relato, ao qual ia apenso esse mapa (Figura 11). Em seu trabalho, contou com a ajuda de D'Anville, o que reconhece no prefácio de sua obra (La Condamine, 2000, p. 34): “M. D’Anville, geógrafo do rei, cuja habilidade é conhecida, me foi de grande vantagem para concatenar e redigir esses materiais esparsos, e enriquecer a minha carta". Em que consistiu essa concatenação; será que D'Anville pode ser considerado coautor do mapa? 


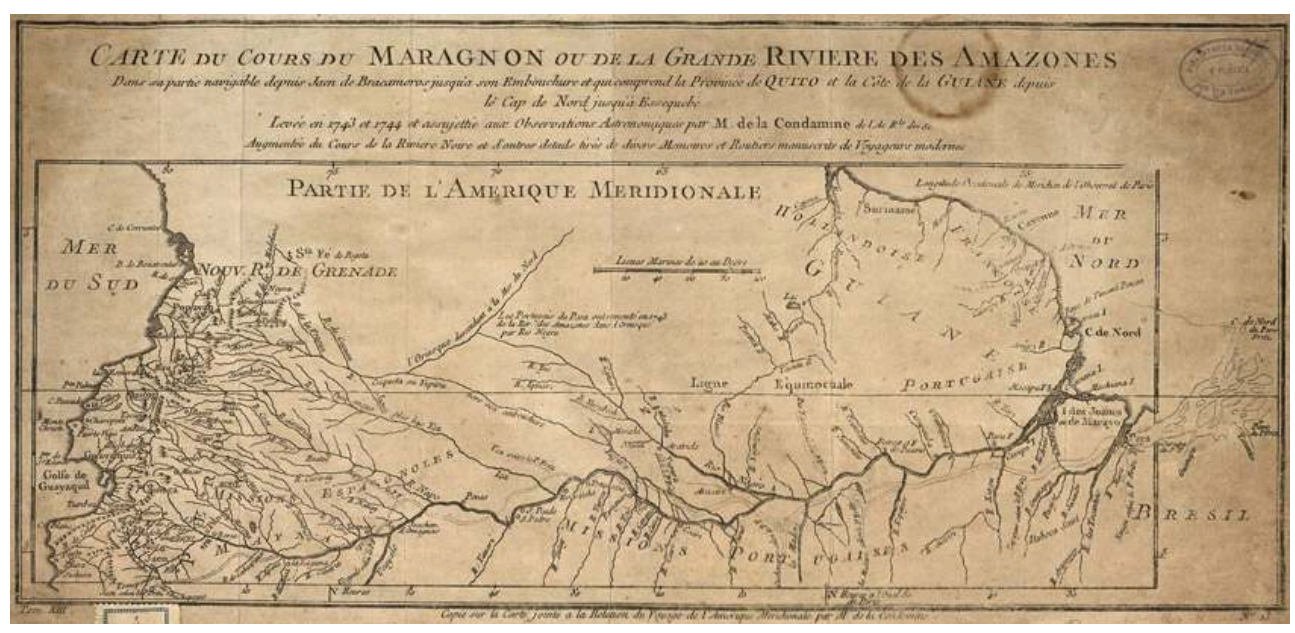

Fonte: Biblioteca Digital da Biblioteca Nacional do Rio de Janeiro. Disponível em: http:// acervo.bndigital.bn.br/sophia/index.asp?codigo_sophia=189

A resposta à primeira pergunta é simples e aparece no citado prefácio: La Condamine mediu e colheu diretamente dados do rio Amazonas, da Província de Quito, contou com alguns dados do Peru e Nova Granada (Colômbia), bem como da costa atlântica, até Paramaribo. $O$ resto das informações foram extraídas, como ele menciona na mesma passagem, "de diversas memórias, jornais (relatos) e notas"; é esse material esparso que foi concatenado pelo geógrafo do rei. Por outro lado, os dados do Relato não coincidem exatamente com os do mapa, talvez em função de um ajuste matemático. Na realidade, La Condamine fez observações bastante precisas na região de partida (Quito ou imediações da base da base geodésica medida) e na região de chegada (Belém e Caiena); mediu somente uma longitude: a da foz do Napo no Amazonas. O método empregado foi o da ocultação dos satélites de Júpiter, aliado à medição ou controle do instante em que o fenômeno ocorreu através de uma pêndula (relógio de pêndulo) e, para os cálculos, uma tabela com a previsão do horário desse acontecimento em Paris. Mas, apesar de todos os cuidados, veio a cometer um erro de mais de $3^{\circ}$ nessa determinação e isso contaminou todo o mapa, tornando-o bastante impreciso; para mais informações, consultar Cintra e Freitas (2011).

E quanto à segunda questão? O mapa é também de D'Anville? Para responder, tenha-se em conta que a projeção empregada (Carta Plana Quadrada) é das mais simples e La Condamine tinha conhecimento e habilidade básicas mais do que suficientes para desenhar por si próprio o mapa. Mas a ajuda do geógrafo real foi, sem dúvida, muito importante na concatenação das outras fontes mencionadas e para um desenho com qualidade visual; a tal ponto que ele pode ser e é considerado o desenhista do mapa. Mas seria injusto considerá-lo como o autor do mapa, sem mais acréscimos. Isso também fica claro quando se tem em conta que os dados de La Condamine, inclusive os erros, foram aceitos sem contestação e crítica nesse momento, coisa que não aconteceu quando D'Anville produziu um novo mapa, analisando e compondo criticamente as fontes. Assim, não pode ser considerado solidário com os erros cartográficos de La Condamine.

O estudo quantitativo mostrou uma alta precisão na latitude $\left(0,1^{\circ}\right)$, com valor semelhante ao que os Padres Matemáticos, em particular Diogo Soares, haviam obtido anos antes. Quanto à longitude, há um erro sistemático de cerca de $1^{\circ}$ e uma precisão 
também da mesma ordem de grandeza $\left(1,1^{\circ}\right)$, um pouco pior que o resultado obtido pelo padre Fritz. Em boa parte, isso se deve ao erro de $3,2^{\circ}$ na foz do rio Napo.

É interessante notar que La Condamine está continuamente comparando seu mapa com o do Padre Fritz, desenhado como pano de fundo do seu e ressaltado em amarelo na Figura 10. O mapa de Fritz é uma referência para ele e, por sua qualidade, uma forma de dizer que o seu mapa é ainda mais preciso que o melhor da época. Para confirmar isso, ele fez um emparelhamento cartográfico dos dois mapas com origem em Jaén (de Bracamoros). Com isso, e tendo em conta que o perfil dos erros de Fritz é crescente, a foz do Amazonas acaba extrapolando a moldura do mapa, reforçando muito a ideia de imprecisão, que só o seu mapa pode identificar.

Para tornar mais clara a comparação, elaboramos o gráfico da figura 12, em que se pode ver o padrão de comportamento das diferenças ou erros em La Condamine (linha vermelha com pontos triangulares): partindo de zero na região das medições precisas no equador, crescente até um máximo na foz do Napo e voltando a decair até zero em Belém, onde esse cientista realizou três boas medições de longitude através de eclipses lunares. Já o comportamento dos dados do padre Fritz muda sensivelmente em função da longitude de partida adotada: a do ajustamento em Jaén, como fez La Condamine, ou a longitude do próprio mapa de Fritz, mas descontando possíveis erros do meridiano de origem. Na primeira opção (linha azul com losangos), o erro começa próximo de zero, que é o de La Condamine, e cresce desmesuradamente até a foz ao atingir $4^{\circ}$. Caso se faça um ajuste melhor (linha verde com quadrados, o erro inicial é inferior a $-2^{\circ}$ e o erro final inferior $\mathrm{a}+2^{\circ}$, com boa parte do rio com erro inferior a $1^{\circ}$.

Figura 12: Comparação da longitude nos mapas de La Condamine e de Fritz

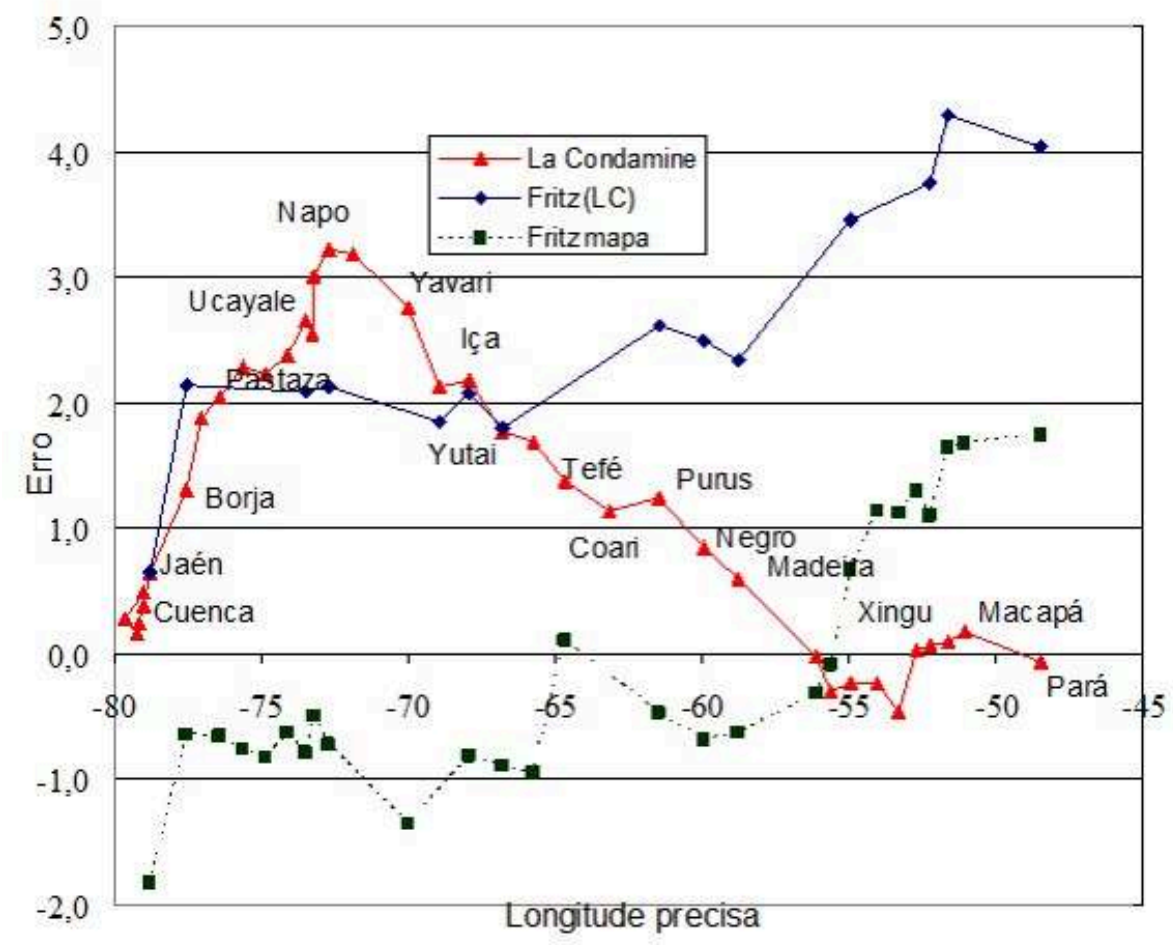

Fonte: Elaboração própria 


\section{O mapa de D'Anville: cartografía de ajustes}

Um passo adiante é a Carte de l'Amérique méridionale (1748), de Bourgignon D'Anville, dividido em três folhas. A primeira delas contém o rio Amazonas e forma, com duas outras, um conjunto da América do Sul contendo uma grande riqueza de detalhes e toponímia, como jamais se havia feito antes. Contratado pelo governo português, esse que foi o primeiro cartógrafo do rei da França, fez uma grande análise crítica das fontes, compondo diversos mapas e informações que lhe eram passadas por seu contratante. Por exemplo, utilizou o mapa do Pe. Fritz (corrigindo a dilatação das longitudes), o mapa de La Condamine (minorando o erro de $3^{\circ}$ na foz do Napo) e diversos outros, como os de Bouguer, Maldonado e Horstman. A precisão situa-se na casa de $0,2^{\circ}$ em latitude e $0,6^{\circ}$ em longitude, como se pode ver em Cintra e Furtado (2011).

Essa melhoria de qualidade foi alcançada em grande parte por contar com os dados e mapas de Delisle (1700 e 1720), sábio que realizou a mais profunda e importante reforma da cartografia mundial, contando com dados de longitudes observadas, através de campanhas patrocinadas pela Academia de Ciências de Paris, como se detalha em Cintra et al. (2016). O Mapa de Delisle, no referente à América do Sul, pode ser consultado na Figura 13, com uma escala de erros. Esses mapas realocaram o perfil e a largura dos continentes levando diversos locais para suas posições corretas. Essa reforma não afetou diretamente o interior do continente, pois nesses sertões não houve campanhas de medição de longitudes, mas, realizando ajustes proporcionais, permitiu melhorar a qualidade de mapas como o do Padre Fritz, que sofriam de um problema de escala: dados proporcionais, mas distendidos por um valor que se pode considerar constante e que pode ser ajustado. 
Figura 13: Delisle, Amerique meridionale, 1763, substancialmente igual ao mapa de 1720

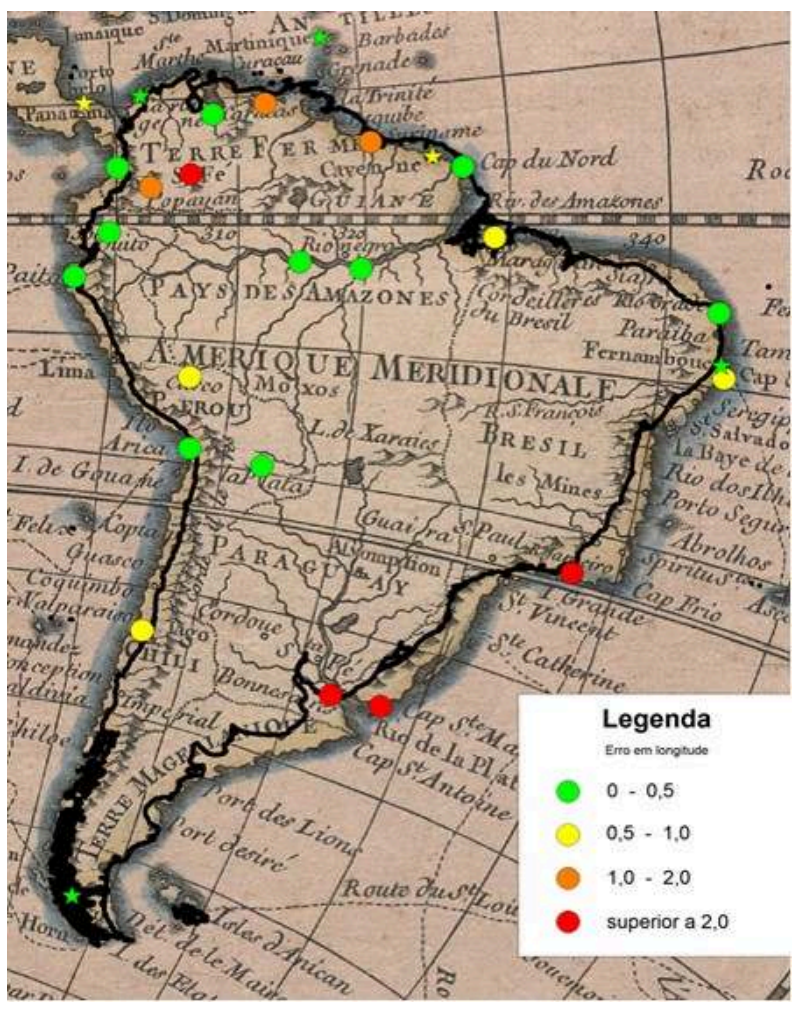

Fonte: 0 autor, a partir do mapa disponível na Biblioteca Digital da Biblioteca Nacional do Rio de Janeiro: http://acervo.bndigital.bn.br/sophia/index.asp?codigo_sophia=62

A correção dos mapas do Pe. Fritz e de La Condamine pode ser vista no gráfico da Figura 14 , em que os erros dos três aparecem representados.

Figura 14: Comparação de erros em longitude nos mapas de Fritz, La Condamine e D'Anville

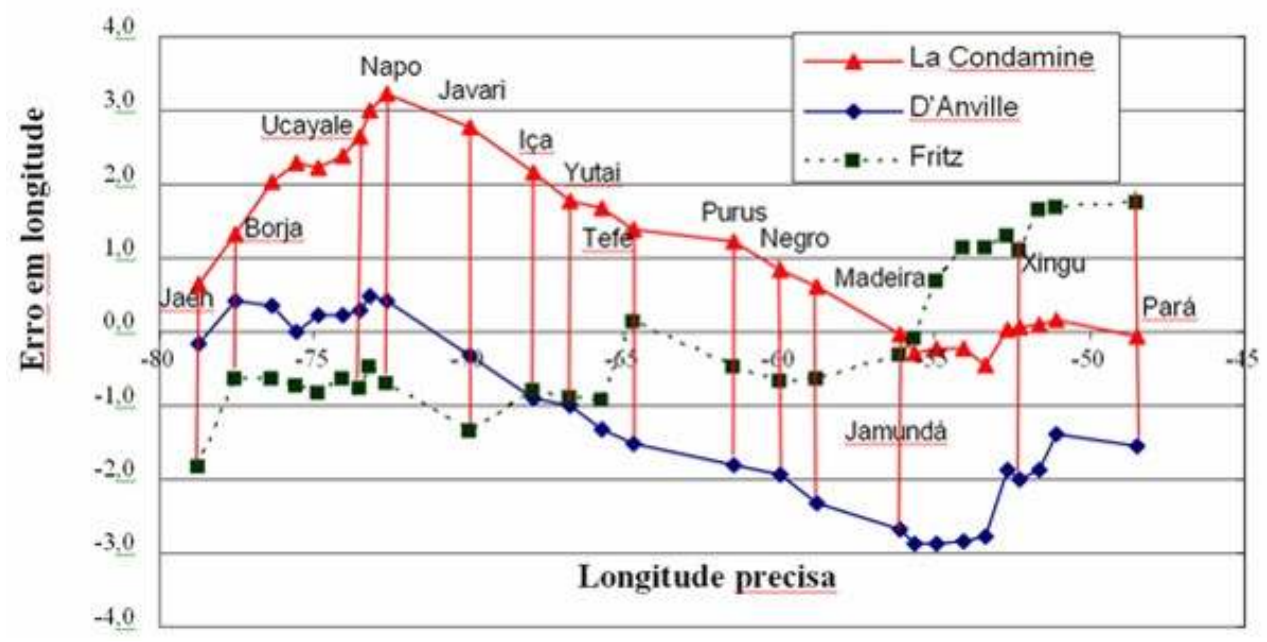

Fonte: $\mathrm{O}$ autor

O Mapa de La Condamine em vermelho com pontos triangulares; o de Fritz em azul com ponto em forma de losangos e o de D'Anville em verde com quadrados. Observa-se a correção que D’Anville fez na foz do Napo e um comportamento muito semelhante, 
ainda que defasado, entre D’Anville e Fritz, da foz do Napo até um ponto após a foz do Madeira e entre Borja e Napo (erro quase constante). A posição de Borja foi tomada de Maldonado. Como apontado em suas memórias, D’Anville se aproveitou dessas duas fontes, sem considerar as coordenadas absolutas, mas sim as diferenças de coordenadas entre rios consecutivos, e fazendo uma montagem. Apesar de tudo, há erros não desprezíveis em D’Anville.

\section{O Mapa das Cortes e seus erros propositais}

O Mapa das Cortes (1749) é quase simultâneo ao mapa de D’Anville (1748), mas apresenta várias inexatidões em termos de longitude, sobre as quais muito se tem discutido (Cintra, 2009, 2012a).

Em resumo, na região amazônica, o Mapa das Cortes efetuou uma ampliação de $3^{\circ}$ na costa atlântica no sentido leste-oeste, entre o cabo de São Roque e Belém do Pará. Isso culminou numa diminuição próxima a $3^{\circ}$ de Belém do Pará até a foz do rio Javari; assim, conseguia devolver à coordenada longitude valores próximos do real em território de Espanha. Isso evitaria uma possível contestação castelhana ao comparar com coordenadas boas de seu território. Mas conseguia, com essa montagem, deslocar para oeste a linha de Tordesilhas e incluir mais território dentro da região portuguesa.

A título de comparação qualitativa final, a Figura 15 apresenta, sobre o mapa de D'Anville (com a linha divisória em marrom tracejado), a fronteira atual do Brasil (em azul) e a fronteira proposta pelo Mapa das Cortes (em vermelho). Essa superposição demonstra a boa aderência entre o mapa atual e o de D'Anville, sobretudo na linha costeira que se estende do rio de São Miguel (Alagoas) até as proximidades da Baía de São Luis; pequenas setas verdes indicam o deslocamento entre a posição atual e a posição nesse mapa.

Figura 15: Comparação visual: fronteiras propostas pelo mapa das Cortes e o de D'Anville

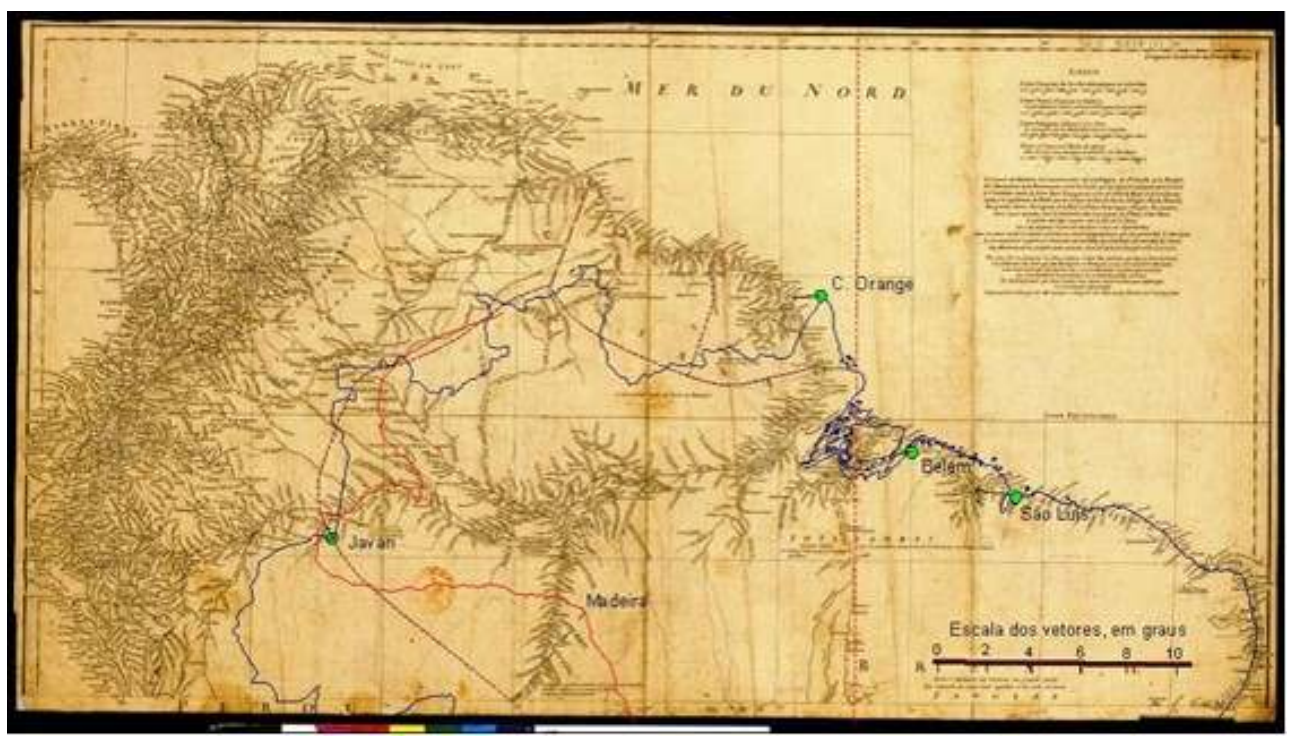

Essas fronteiras e suas diferenças são importantes quando se tem em conta que representam duas propostas diferentes para o Tratado de Madri, uma proveniente de D. Luís da Cunha e concretizada nesse mapa de D'Anville e outra, orientada por Alexandre 
de Gusmão, materializada no Mapa das Cortes. Essa última, que acabou prevalecendo, conhecia a cartografia de D'Anville e sabia de sua maior exatidão, principalmente relativa às longitudes e extensão do Amazonas, mas não as adotou, pois pretendia-se mostrar aos espanhóis uma área extra Tordesilhas menor do que ela era na realidade. Por outro lado, a proposta associada a Alexandre de Gusmão não define a fronteira com as Guianas (não interessava ao Tratado com os espanhóis) enquanto a de D. Luís definia uma posição menos ambiciosa do que se conseguiu; concretamente transferia para a França mais da metade do atual Amapá e parte do Pará; teria D’Anville influência nisso?

\section{Os mapas e suas camadas}

Uma discussão final sobre os mapas, servindo-nos do Terra Brasilis (Figura 16), é útil para mostrar como existem várias camadas de informações e ângulos de observação.

Figura 16: Lopo Homem, Pedro e Jorge Reinel, Terra Brasilis, 1519

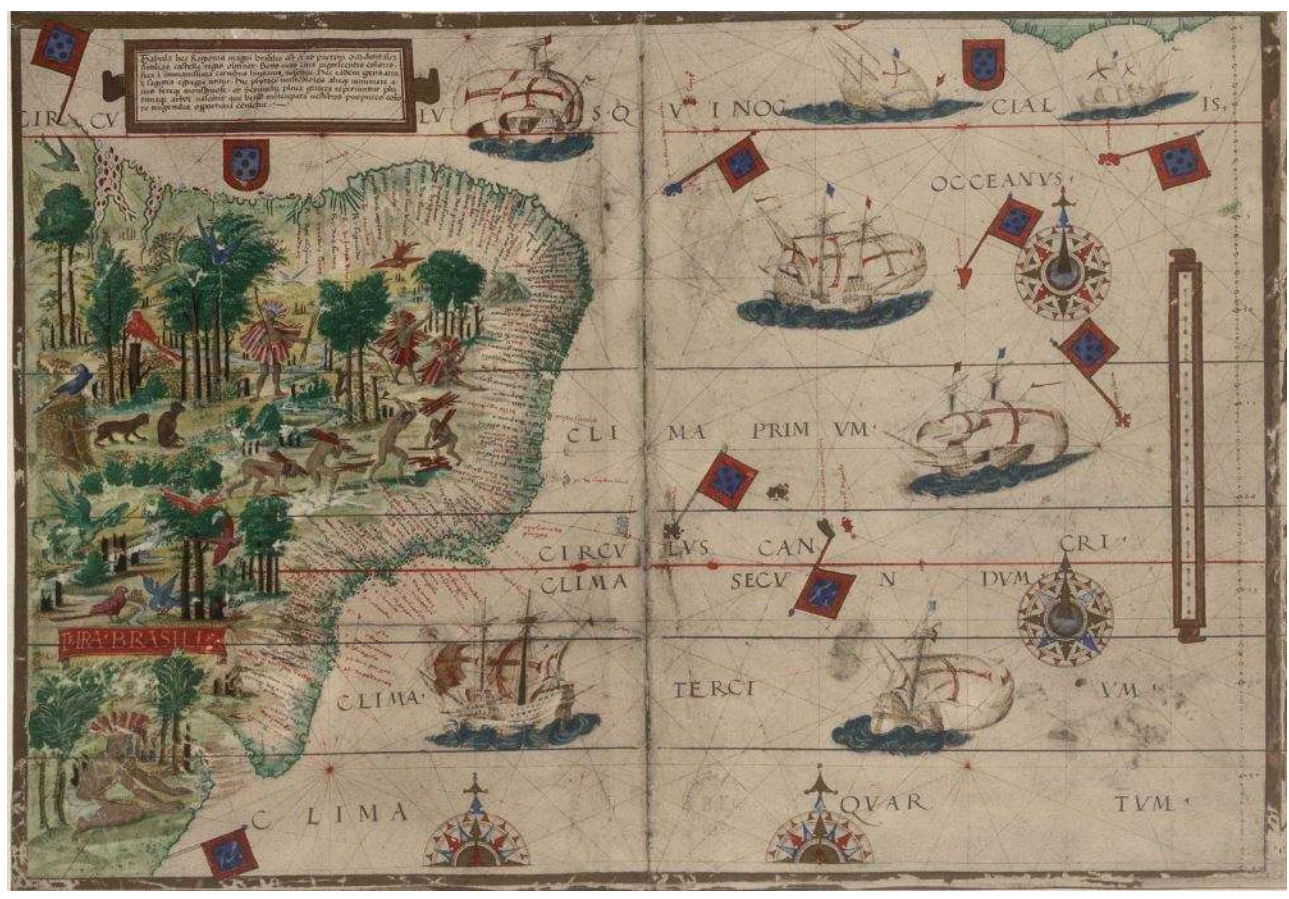

Fonte: cópia da Biblioteca Nacional do Rio de Janeiro. Disponível em: http://acervo.bndigital.bn.br/ sophia/index.asp?codigo_sophia=237

Uma primeira leitura pode destacar a ocupação indígena do território e a atividade de extração e comércio do pau-brasil, ou a riqueza da fauna e da flora brasileira. Outra leitura pode destacar a bela plástica das iluminuras de Antônio de Holanda: bandeiras, caravelas etc. Uma leitura estritamente cartográfica ou geométrica pode ver os elementos de navegação e geometrização do espaço: rosa dos ventos, escala de latitudes, equador e trópico. O estudo toponímico poderá ressaltar a cartela e as localidades ao longo de toda a costa brasileira, refletindo o conhecimento que se tinha na época. Cada estudo desses pode ser aprofundado; para tomar só um exemplo, na Figura 17, destacamos sobre esse mesmo mapa, as construções geométricas, superpondo as linhas das 16 rosas dos ventos e as 32 direções de cada uma: revela-se um mundo que estava implícito e escondido e que ajuda a entender a forma como os 
mapas eram construídos e copiados, e aponta para os instrumentos utilizados. Isso quer dizer que existem camadas mais profundas em cada dimensão do mapa.

Figura 17: A geometria subjacente ao Terra Brasilis

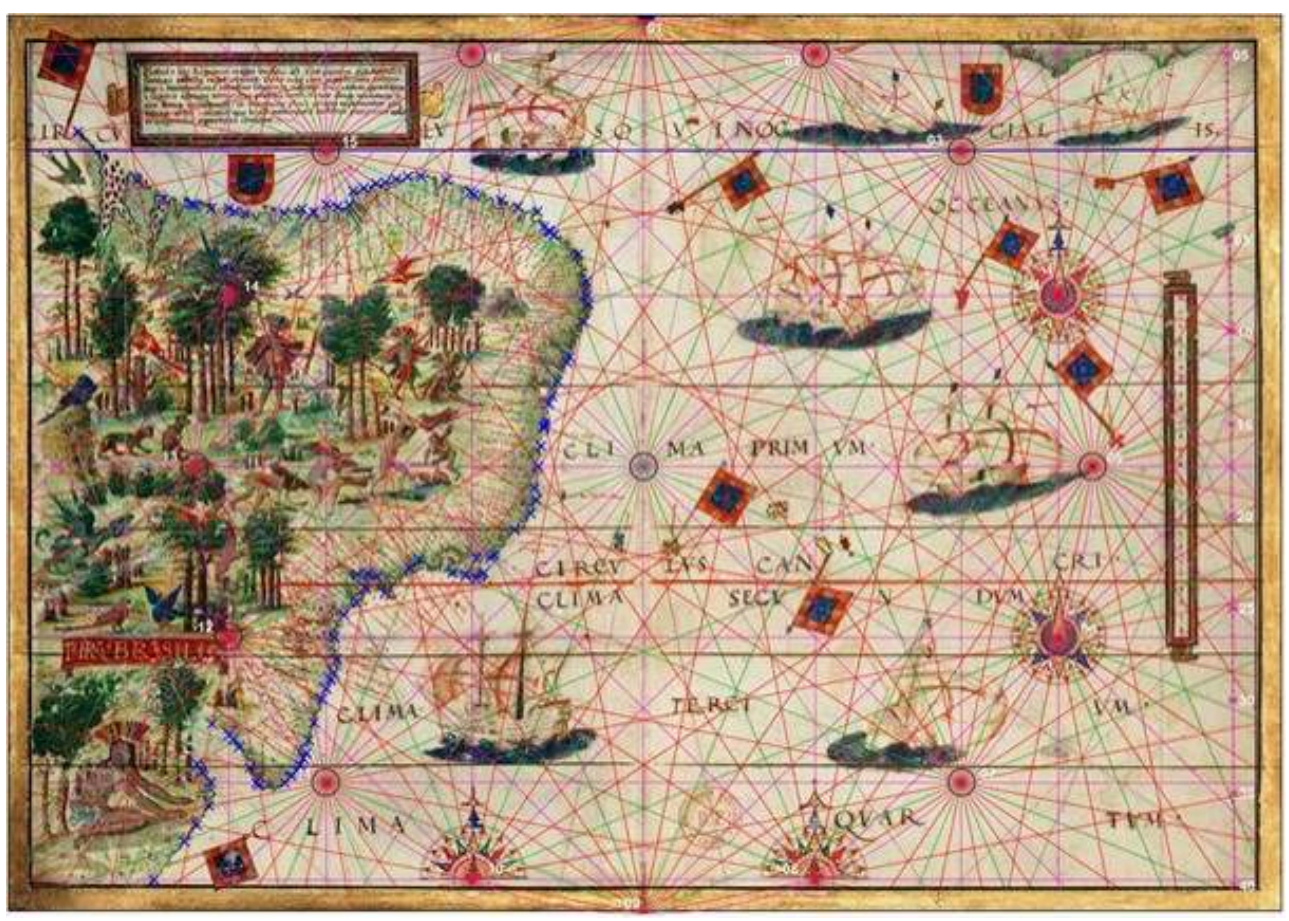

Fonte: 0 autor, sobre o mapa da Figura 16

Dados históricos podem ser acrescentados: os autores são Lopo Homem, com a ajuda de Pedro e Jorge Reinel, cartógrafos negros; o mapa é de 1519 e foi um presente de rei para rei. Mas não se pode desconhecer a principal mensagem que D. Manuel, o venturoso, está querendo transmitir a Francisco I da França. As embarcações em profusão, com a cruz da ordem de Cristo nas caravelas, estão comunicando: esse mar é meu; as bandeiras colocadas em ilhas dizem que elas são nossas; os escudos e a toponímia na costa, seguindo a lógica de que nomear é possuir, reclamam a posse do território; as bandeiras na foz do Amazonas e do Prata indicam o limite pretendido para as terras, com a linha de Tordesilhas deslocada para oeste; os índios com atividade no interior apontam para o essa riqueza, que vocês, franceses, estão contrabandeando, mas ela está em nosso território e, portanto, é nossa. Francisco I aceitou o presente, mas não deixou de pedir que lhe mostrassem a cláusula do testamento de Adão que o excluiu de tal partilha do mundo entre Portugal e Espanha. De fato, a França estabeleceu-se nas regiões antártica e equinocial.

Inúmeros outros exemplos poderiam ser aduzidos da interrelação entre política e cartografia: decisões que alteraram completamente a toponímia da região amazônica; mapas sendo utilizados como instrumento de disputa de território, como já destacamos.

Todas as diversas camadas, ângulos e olhares são dignos de nota, consideração e estudo e, por sua própria natureza, os estudos tornam-se interdisciplinares. Os mapas, além de seu significado cartográfico, são um documento e uma fonte histórica de primeira grandeza, reveladora da sociedade que o produziu e da qual sofreu impactos. 


\section{Conclusões}

46 A disponibilidade de mapas históricos em meio digital cresceu muito nos últimos anos, mas ainda é pequena a parcela disponível, basta pensar na quantidade de mapas ainda por digitalizar no Itamaraty e na Biblioteca do Exército, por exemplo. Mas o que existe já permite muitos estudos.

47 A metodologia apresentada é certamente interativa e tem sua fluidez, na medida em que se incorporam novos mapas ou coleções no conjunto das observações. Sempre pode aparecer um mapa anterior àquele que era considerado como protótipo ou estruturante. Por outro lado, os protótipos se aperfeiçoam com o tempo, como aconteceu com a cartografia portuguesa da era das chamadas grandes navegações e o estudo de sua evolução é um tema de pesquisa promissor.

A aplicação da metodologia é mais aderente aos mapas manuscritos, que, apesar de poucos se comparado a outros tipos, são os mais antigos. Isso porque os mapas impressos evoluem nas editoras ou casas de impressão de Atlas, que muitas vezes compraram clichês de outras.

No entanto, essa forma de trabalhar permite agrupar os mapas por classes, tipos ou semelhanças e ajudam a contar a história e a gênese dos mapas. Em se tratando dos primórdios, eles guardam uma estreita relação com as viagens exploratórias e com os instrumentos e técnicas mais ou menos precisos que estavam disponíveis à sua época de produção; explicam-se pela evolução tecnológica e ajudam a contar a histórica desses equipamentos: do astrolábio e da bússola até o moderno sistema de posicionamento por satélite, passando pela pêndula, pelo cronômetro e pela observação das ocultações dos satélites de Júpiter.

Dispor os mapas em uma sequência cronológica e identificar os principais é uma maneira de estudar a cartografia de uma região e a história de seu desenvolvimento econômico, social e da ocupação territorial.

51 A cartografia clássica, a digital e a metodologia numérica ajudam a entender os mapas, num processo de precisões crescentes. Ajudam também a identificar distorções propositais, como no Mapa das Cortes, para facilitar a aprovação do Tratado de Madri. Por esse motivo, o estudo qualitativo e morfológico, através de técnicas de leitura de imagens, completa-se pelo estudo quantitativo.

História e Cartografia complementam-se e se esclarecem mutuamente. Um mapa, como demonstrado a partir de alguns exemplos, possui diversas camadas, e cada uma delas pode ser dissecada. Olhares diversos são bem-vindos para obter uma visão mais abrangente do mapa e da civilização que o produziu. 


\section{BIBLIOGRAFIA}

Acuña, Cristobal de (1641). Nuevo descubrimiento del gran rio de las Amazonas. Madrid: Imprensa del Reyno. Disponível em: https://digital.bbm.usp.br/view/?45000008034\&bbm/2587\#page/1/mode/ 2 up

Cintra, Jorge. P. (2012a). "O mapa das cortes e as fronteiras do Brasil”. Boletim de Ciências Geodésicas (Online), v. 18, pp. 421-445. Disponível em: https://www.scielo.br/scielo.php? script=sci_arttext\&pid=S1982-21702012000300005\&lng=en\&nrm=iso. Acesso em: 17 out. 2020.

Cintra, Jorge P. (2012b). “Digital Cartography and Historical Maps: techniques, applications and peculiarities”. RBC. Revista Brasileira de Cartografia (Online), v. 64, pp. 901-918. Disponível em: http://www.seer.ufu.br/index.php/revistabrasileiracartografia/article/view/43830. Acesso em: 17 out. 2020.

Cintra, Jorge P. (2009). “O Mapa das Cortes: perspectivas cartográficas”. Anais do Museu Paulista. [online]. 2009, v. 17, n.2, pp. 63-77. Disponível em: http://www.scielo.br/pdf/anaismp/ v17n2/05.pdf. Acesso em: 17 out. 2020.

Cintra, Jorge P. (2011). “Magni Amazoni Fluvii: o mapa do Conde de Pagan”. In: Simpósio Brasileiro de Cartografia Histórica, 2011, Paraty. Anais do 1ํㅗํósio Brasileiro de Cartografia Histórica. Belo Horizonte: Centro de Referência em Cartografia Histórica UFMG, 2011. v. 1. pp. 1-20. Disponível em: https://www.ufmg.br/rededemuseus/crch/simposio/ CINTRA_JORGE_PIMENTEL_1.pdf. Acesso em: 17 out. 2020.

Cintra, Jorge P. (2015). “Técnicas de leitura de mapas históricos: uma proposta”. RBC. Revista Brasileira de Cartografia (Online), v. 67, pp. 773-786. Disponível em: http://www.seer.ufu.br/ index.php/revistabrasileiracartografia/article/view/49120. Acesso em: 17 out. 2020.

Cintra, Jorge P. (2016). “Uma leitura de mapas à luz do método iconológico”. In: $3^{\circ}$ Simpósio Brasileiro de Cartografia Histórica, 2016, Belo Horizonte. Anais do $3^{\circ}$ Simpósio Brasileiro de Cartografia Histórica. Belo Horizonte: CRCH-UFMG, v. 1. pp. 386-395. Disponível em: https:// www.ufmg.br/rededemuseus/crch/simposio2016/pdf/34JorgeCintra_3SBCH.pdf. Acesso em: 17 out. 2020.

Cintra, Jorge P.; Oliveira, Rafael; Filho, Flávio Guilherne (2016). “A reforma cartográfica de Delisle e seu impacto na Cartografia da América do Sul e do Brasil”. In: $3^{\circ}$ Simpósio Brasileiro de Cartografia Histórica, 2016, Belo Horizonte. Anais do $3^{\circ}$ Simpósio Brasileiro de Cartografia Histórica. Belo Horizonte: CRCH/UFMG, v. 1. pp. 192-201. Disponível em: https:// www.ufmg.br/rededemuseus/crch/simposio2016/pdf/17Rafaeloliveira-etal_3SBCH.pdf. Acesso em: 17 out. 2020.

Cintra, Jorge P.; Freitas, Janaina C. (2011). “Sailing Down the Amazon River: La Condamine's Map”. Survey Review, v. 43, pp. 550-566. Disponível em: https://www.tandfonline.com/doi/abs/ 10.1179/003962611X13117748892119. Acesso em: 17 out. 2020.

Cintra, Jorge P.; Furtado, Junia F. (2011). “A Carte de l'Amérique Méridionale de Bourguignon D'Anville: eixo perspectivo de uma cartografia amazônica comparada”. Revista Brasileira de História (Online), v. 31, pp. 273-316. Disponível em: https://www.scielo.br/pdf/rbh/v31n62/ a15v31n62.pdf. Acesso em: 17 out. 2020.

Cintra, Jorge. P.; Oliveira, Rafael H. de. (2014). "Nicolas Sanson and his Map: The Course of the Amazon River”. Acta Amazonica (Impresso), v. 44, pp. 353-365. Disponível em: https:// 
www.scielo.br/scielo.php?script=sci_arttext\&pid=S0044-59672014000300008\&lng=en\&nrm=iso. Acesso em: 17 out. 2020.

La Condamine, Charles-Marie de (1701-1774). “Viagem na América Meridional descendo o rio das Amazonas”. In: Coleção O Brasil Visto por Estrangeiros. Brasília: Senado Federal, 2000. 204 p.

Pagan, Blaise François (1656). Relation Historique et Géographique de la Grande Rivière das Amazones dans l' Amérique, 1656, s/d, Paris. Tradução inglesa: An Historical \& Geographical Description of the Contry \& River of the Amazones in America, por William Hamilton, 1660, Londres. Disponível em: http://eebo.chadwyck.com. Acesso em: 17 out. 2020.

\section{RESUMOS}

Apresenta-se uma metodologia para o estudo da evolução da cartografia de um determinado território. Como exemplo de aplicação, adaptável a outros casos, escolheu-se a região amazônica, com foco no rio Amazonas, de 1500 a 1750. Esse desenvolvimento foi possível graças à relativamente recente disponibilização massiva de mapas em meio digital, por instituições como a Biblioteca Nacional (Brasil) e a John Carter Brown Library. Essa metodologia consiste na ordenação cronológica dos mapas, no exame de seu conteúdo e formas morfológicas e na busca de mapas estruturantes, aqueles que serviram de protótipo para outros. Parte-se do princípio de que não existe mapa sem informação e toda informação cartográfica tem sua origem, mesmo que seja a imaginação do cartógrafo ou mitos coletivos. Para esse estudo, os erros e equívocos, comparados a mapas atuais, são muito eloquentes para identificar cópias; e a evolução da tecnologia, joga um papel decisivo. Finalmente, eventos sociais e políticos refletem-se nos mapas, cuja riqueza exige um estudo sob diversos ângulos e aspectos. A cartografia histórica e a história da cartografia somam-se e devem ser vistas como complementares e não visões excludentes.

A methodology is presented to study the evolution of cartography in each territory. As an application example, adaptable to other cases, the Amazon region was chosen, focusing on the Amazon River, from 1500 to 1750 . This development was only possible due to the relatively recent massive availability of maps in digital media, by institutions such as Biblioteca Nacional (Brazil) and the John Carter Brown Library. This methodology consists in a chronological ordering of the maps, the examination of their content and the morphological forms and the search for structuring maps, those that served as a prototype for others. It is assumed that there is no map without information and all cartographic information has its origin, even if it is the cartographer's imagination or collective myths. For this study, errors and misconceptions, compared to current maps, are very eloquent in identifying copies; and the evolution of technology, plays a decisive role. Finally, social and political events are reflected in the maps, whose richness requires study from different angles and aspects. Historical cartography and the history of cartography joined efforts and should be seen as complementary and not excluding views.

Se presenta una metodología para estudiar la evolución de la cartografía en un territorio determinado. Como ejemplo de aplicación, adaptable a otros casos, se eligió la región amazónica, con foco en el río Amazonas, desde 1500 hasta 1750. Ese desarrollo fue posible gracias a la relativamente reciente disponibilidad masiva de mapas en medios digitales, por instituciones como la Biblioteca Nacional (Brasil) y la Biblioteca John Carter Brown. Esa metodología consiste en el ordenamiento cronológico de los mapas, el examen de su contenido y formas morfológicas y la búsqueda de mapas estructurantes, los que sirvieron de prototipo para otros. Se asume que no hay mapa sin información y toda información cartográfica tiene su origen, aunque sea la imaginación del cartógrafo o mitos colectivos. Para este estudio, los errores y conceptos 
erróneos, en comparación con los mapas actuales, son muy elocuentes para identificar copias; y la evolución de la tecnología juega un papel decisivo. Finalmente, los hechos sociales y políticos se reflejan en los mapas, cuya riqueza requiere un estudio desde diferentes ángulos y aspectos. La cartografía histórica y la historia de la cartografía se suman y deben verse como puntos de vista complementarios y no excluyentes.

Une méthodologie est présentée pour étudier l'évolution de la cartographie sur un territoire. Comme exemple d'application, adaptable à d'autres cas, la région amazonienne a été choisie, en se concentrant sur le fleuve Amazone, de 1500 à 1750. Cette évolution a été possible grâce à la disponibilité massive relativement récente de cartes en média numérique, par des institutions comme la Bibliothèque nationale du Brésil et la John Carter Brown Library. Cette méthodologie consiste en l'ordre chronologique des cartes, l'examen de leur contenu et des formes morphologiques et la recherche de cartes structurantes, celles qui ont servi de prototype à d'autres. On suppose qu'il n'y a pas de carte sans information et que toute information cartographique a son origine, même s'il s'agit de l'imagination du cartographe ou des mythes collectifs. Pour cette étude, les erreurs et les idées fausses, par rapport aux cartes actuelles, sont très éloquentes pour identifier les copies; et l'évolution de la technologie, joue un rôle décisif. Enfin, les événements sociaux et politiques se reflètent dans les cartes dont la richesse nécessite une étude sous différents angles et aspects. La cartographie historique et l'histoire de la cartographie s'additionnent et doivent être considérées comme complémentaires et non exclusives.

\section{ÍNDICE}

Keywords: methodology, comparative cartography studies, comparative cartography history, Amazon region, Amazon river

Índice cronológico: 1500-1750

Índice geográfico: Rio Amazonas

Mots-clés: méthodologie, évolution cartographique, histoire de la cartographie comparée, région amazonienne, fleuve Amazone

Palabras claves: metodología, evolución cartográfica, historia de la cartografía comparada, región amazónica, rio Amazonas

Palavras-chave: metodologia, evolução cartográfica, história da cartografia comparada, região amazônica, rio Amazonas

\section{AUTOR}

\section{JORGE PIMENTEL CINTRA}

Escola Politécnica da USP e Museu Paulista da USP

jpcintra@usp.br 